\title{
Inibição e inativação in vitro de Salmonella spp. com extratos de plantas com indicativo etnográfico medicinal ou condimentar
}

\author{
[In vitro inhibition and inactivation activity of Salmonella spp. by plant extracts \\ with spicy or medicinal ethnographic indicative]

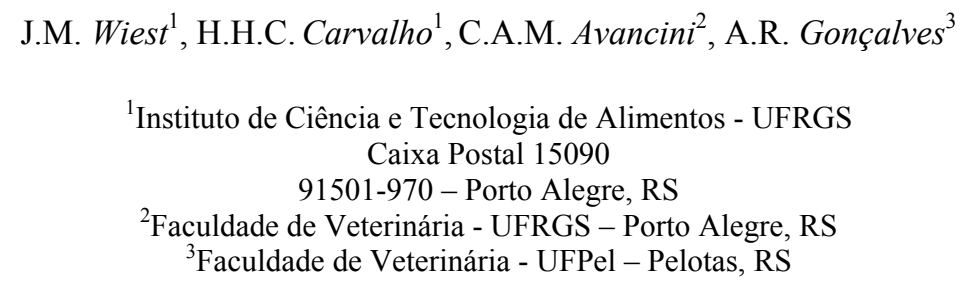

\section{RESUMO}

Determinou-se in vitro a intensidade de atividade de inibição bacteriana e a intensidade de atividade de inativação bacteriana, por meio de testes de diluição e suspensão em sistema de tubos múltiplos, de diferentes extratos, aquosos ou alcoólicos/hidroalcoólicos, de 86 plantas com indicativo etnográfico medicinal ou condimentar acessadas na região metropolitana de Porto Alegre, Rio Grande do Sul, frente a Salmonella spp., ou $S$. enteritidis ATCC $\mathrm{n}^{\circ}$ 13076, ou $S$. cholera-suis ATCC nº10708, ou S. gallinarum CPVDF-SAA/RS/BR, em doses-desafio de $\leq 10^{7}$ UFC. $\mathrm{mL}^{-1}$. Cinquenta plantas apresentaram alguma atividade seletiva antissalmonela, e 37 nenhuma atividade. Discute-se a validade da ferramenta etnográfica na prospecção de fatores de proteção antibacteriana em plantas, bem como a influência da inibição/inativação na preditividade do diagnóstico bacteriológico.

Palavras-chave: planta medicinal, atividade antibacteriana, inibição, inativação, Salmonella spp.

\begin{abstract}
The in vitro intensity of bacterial inhibition activity of diverse extracts (aquous, alcoholic, or hydroalcoholic) from 86 plants with medicinal and spicy ethnographic indicative, from Porto Alegre City, Rio Grande do Sul State, Brazil, were determinated in Salmonella spp. (S. enteritidis ATCC n.13076, S. cholera-suis ATCC n. 10708, or S. gallinarum CPVDF-SAA/RS/BR) in challenge dose $\leq 10^{7} C F U . m L^{-1}$. Extracts of fifty plants presented some anti-salmonella selective activity, while the other 36 extracts presented no activity. It is discussed the validity of ethnographic search instruments in the prospection of anti-bacterial protection factors in plants, as well the influence of inhibition/inactivation results in the predictivity of bacteriological diagnostic.
\end{abstract}

Keywords: medicinal plant, antibacterial activity, inhibition, inactivation, Salmonella spp.

\section{INTRODUÇÃO}

A importância do gênero Salmonella em saúde coletiva permanece em evidência, considerando sua resistência no meio externo, mais especificamente em resíduos, dejetos, alimentos para consumo humano e animal, solo e águas de abastecimento, manifestando-se tanto individualmente como em centenas de indivíduos por meio de surtos. Sua verdadeira incidência é difícil de ser avaliada, considerando as deficiências da vigilância epidemiológica e de sua relação com a notificação, o que não impede o aumento significativo do número de focos constatados (Acha e Szyfres, 2003).

Recebido em 25 de abril de 2008

Aceito em 15 de outubro de 2008

E-mail: jmwiest@ufrgs.br

Apoio: $\mathrm{CNPq}$ 
Nesse sentido, em saúde e produção animal, com consequente repercussão na cadeia alimentar, Castagna et al. (2004) demonstraram a presença de Salmonella sp. no trato intestinal e em tonsilas/linfonodos submandibulares de suínos, em $79 \%$ das amostras utilizadas no preparo de embutidos, constituindo importante fator de risco para a contaminação de carcaças utilizadas na fabricação desses produtos.

Silva et al. (2006) descreveram a difusão da infecção em um rebanho suíno por Salmonella sp. por meio de isolamentos e sorologia, desde a fase de maternidade, creche e terminação, comprovando a crescente contaminação dos animais, inclusive em amostras de ração alimentar, concluindo que a terminação constitui o ponto crítico de contaminação e a ração uma importante fonte de infecção.

$\mathrm{Na}$ epidemiologia e profilaxia de doenças transmissíveis, a pesquisa de fatores de proteção sustentáveis, alternativos, dirigida a recursos naturais renováveis, como plantas com indicativo medicinal, condimentar ou aromático, constitui prioridade segundo a Organização Mundial da Saúde/Conferências Mundiais de Saúde (Akerele, 1988, 1993; Cultura..., 1984, 1985, 1990), com ênfase aos aspectos culturais tradicionais envolvidos e sua relação com a atenção básica em saúde coletiva, em alimentos/alimentação e em saúde e produção animal.

No Brasil, a pesquisa da atividade antimicrobiana em plantas com indicativo medicinal, condimentar ou aromático vem merecendo ênfase, como demonstram os trabalhos desenvolvidos por Lemos et al. (2000) e Avancini e Wiest (2008a), que pesquisaram especificamente a atividade bactericida de macela (Achyrocline satureoides, Lam. DC Compositae) e de escadinha ou sinapismo (Hypericum caprifoliatum, Cham. Schlecht Guttiferae), respectivamente, relacionada com mastites bovinas; Avancini e Wiest (2008b), que estudaram 36 plantas com indicativo etnográfico medicinal da Mata Atlântica residual em Porto Alegre, com ênfase à etnomedicina veterinária, etnosotaxia e etnoterapêutica de doenças de pele como referência para a seleção e avaliação preliminar da atividade antibacteriana; Carvalho et al. (2005), que avaliaram situações envolvendo bacteriostasia e bactericidia de 32 plantas com indicativo etnográfico condimentar, incluindo Salmonella sp., indicando 12 plantas com efetiva e seletiva atividade antibacteriana; Sousa e Wiest (2007), que pesquisaram especificamente bacteriostasia e bactericidia em diferentes extratos de garupá (Aloysia gratissima), também incluindo Samonella sp. Na área de patologia humana, Alvarenga et al. (2007) testaram extratos aquosos e etanólicos de diferentes plantas sobre bactérias patogênicas, entre elas Salmonella cholera-suis.

O Grupo de Pesquisa Alimentos de Origem Animal/CNPq/MCT/Brasil vem se dedicando, desde 1995, à prospecção preliminar, dentro do princípio da triagem com droga crua, de atividade antibacteriana em extratos de plantas com indicativo etnográfico medicinal, condimentar ou aromático. $\mathrm{O}$ presente trabalho teve por objetivo sintetizar resultados relativos a Salmonella spp., oriundos de trabalhos acadêmicos do grupo, discutir a probabilidade de interveniência da inibição/inativação constatadas no diagnóstico preditivo dessa bactéria em alimentos, bem como a validação da ferramenta etnográfica na prospecção de recursos em saúde.

\section{MATERIAL E MÉTODOS}

Foram testadas três sorotipos de Salmonella, dois padrões American Type Culture Collection (ATCC), respectivamente $S$. enteritidis (ATCC 13076) e $S$. cholera-suis (ATCC 10708), e um isolado de campo de $S$. gallinarum, cedida pelo Laboratório de Patologia Animal/Bacteriologia do Centro de Pesquisa Veterinárias Desidério Finamor da Secretaria de Agricultura e Abastecimento, RS. As amostras foram mantidas em bacterioteca, ativadas em meio Brain Heart Infusion $(\mathrm{BHI}-\mathrm{B})^{1}$ a $37^{\circ} \mathrm{C}$ em aerobiose, atingindo os inóculos no mínimo $\geq 10^{7} \mathrm{UFC} . \mathrm{mL}^{-1}$, entre 18 e 24 horas.

Por meio do método qualitativo de etnografia rápida (Etkin, 1993), fez-se o resgate de saberes e fazeres relacionados às 86 plantas com a participação de 16 informantes (remanescentes quilombolas, ameríndios, imigrantes teutos, de curadores tradicionais e de voluntários da Pastoral da Saúde), registrando-se seu consentimento livre e esclarecido (Clotet et al., 2000), como orienta o Decreto $\mathrm{n}^{\circ} 4.339$ da

${ }^{1}$ Brain-Hearth Infusion Broth - Acumedia - Michigan, EUA. 
Política Nacional de Biodoversidade, Diretriz $\mathrm{n}^{\mathrm{o}}$ 2 (XII), de 22 de agosto de 2002.

Todas as plantas foram acessadas na região metropolitana de Porto Alegre, RS, identificadas botanicamente e encaminhadas como exsicatas (Ming, 1996) para registro no Herbário do Departamento de Botânica, do Instituto de Biologia da UFRGS.

As diferentes plantas foram utilizadas imediatamente ainda verdes, ou secas à sombra sob ventilação e, assim, armazenadas para uso posterior. Os diferentes extratos vegetais foram obtidos segundo a Farmacopeia Brasileira (Farmacopeia..., 1959), ocorrendo ou não a reposição/reidratação posterior, constituindo decoctos (plantas verdes ou secas), alcoolaturas (plantas verdes) ou hidroalcoolaturas (plantas secas), as duas últimas submetidas à destilação fracionada sob pressão reduzida em aparelho de rota-vapor.

Para a avaliação da atividade antibacteriana dos diferentes extratos estudados, expressa como intensidade de atividade de inibição bacteriana (IINIB) e de intensidade de atividade de inativação bacteriana (IINAB), utilizaram-se os testes de diluição e de suspensão (Deutsche..., 1980, citado por Schliesser e Strauch, 1981), com base na técnica do sistema de tubos múltiplos, modificada por Avancini (2002), confrontando os diferentes extratos vegetais com oito diluições seriais logarítmicas $\left(10^{-1}\right.$ a $10^{-8} \mathrm{UFC} / \mathrm{mL}^{-1}$ ) das diferentes salmonelas em teste, controlando por plaqueamento $\mathrm{o}$ crescimento bacteriano específico, bem como contaminações intervenientes. Entendeu-se por IINIB o resultado do confronto da salmonela com o extrato vegetal em meio específico, e por IINAB o mesmo resultado, porém sob influência dos desinibidores bacterianos (Deutsche..., 1980, citado por Schliesser e Strauch, 1981). Os resultados de IINIB e de IINAB foram representados por variáveis ordinais arbitrárias, que assumiram valores de oito a zero, indicando a intensidade dessas atividades e de suas correspondentes diluições/doses infectantes dos inóculos de salmonela. Dessa maneira, atribuiuse o valor máximo oito quando a atividade de inibição ou de inativação de uma determinada concentração do extrato vegetal correspondeu a $10^{-1}$ ou a $10^{7} \mathrm{UFC} . \mathrm{mL}^{-1}$ (partindo de uma cultura ativada com, no mínimo, $10^{8} \mathrm{UFC} \cdot \mathrm{mL}^{-1}$ ), ou valor zero, quando da verificação de nenhuma atividade, tanto de inibição como de inativação, demonstrada pela concentração do extrato vegetal em teste.

Em todos os testes, avaliaram-se os resultados de IINIB e de IINAB por meio de análise estatística descritiva e análise de variância, com complementação pelo teste Duncan e teste t.

\section{RESULTADOS E DISCUSSÃO}

Entre 86 plantas com indicativo etnográfico medicinal, condimentar ou aromático acessadas na região metropolitana de Porto Alegre, RS, 50 apresentaram alguma atividade antissalmonela (Tab. 1), enquanto as demais 36 não apresentaram atividade, nas condições dos diferentes experimentos (Tab. 2), embora apresentassem intenso referencial etnográfico de uso em agravos à saúde envolvendo agentes infecciosos, ferimentos/cicatrização, manifestações gastrintestinais, conservação de alimentos, promoção da saúde e da produção animal.

Dentre as plantas acessadas, nas condições dos diferentes experimentos, por atingirem valores arbitrários atribuídos em grau máximo, 8, tanto em IINIB como em IINAB sobre Salmonella spp., destacam-se alho-porró (Allium porrum), alho-nirá (Allium tuberosum), macela (Achyrocline satureoides), pimenta-malagueta (Capsicum frutescens), erva-mate (Ilex paraguariensis), orégano (Origanum applii), sálvia (Salvia oficinalis) e o chinchilho (Tagetes minuta), entre outras. 
Tabela 1. Plantas com indicativo etnográfico medicinal ou condimentar acessadas na região metropolitana de Porto Alegre, RS, que apresentaram alguma inibição ou inativação frente a Salmonella sp., segundo extração, dose-desafio e tempo de exposição

\begin{tabular}{|c|c|c|c|c|c|c|c|c|c|}
\hline \multicolumn{2}{|c|}{ Denominação } & \multirow[b]{2}{*}{ 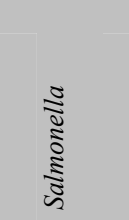 } & \multirow[b]{2}{*}{ 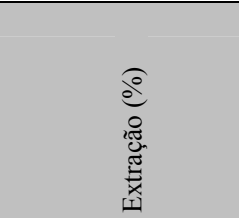 } & \multirow[b]{2}{*}{ 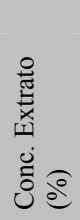 } & \multirow[b]{2}{*}{ 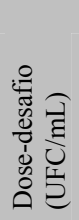 } & \multirow[b]{2}{*}{ 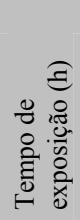 } & \multicolumn{2}{|c|}{ Resultado } & \multirow[b]{2}{*}{$\begin{array}{l}\stackrel{0}{0} \\
\text { II }\end{array}$} \\
\hline : & 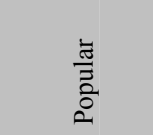 & & & & & & 氠 & 空 & \\
\hline \multirow{5}{*}{$\begin{array}{l}\text { Achyrocline } \\
\text { satureoides (Lam.) } \\
\text { DC COMPOSITAE }\end{array}$} & \multirow[t]{5}{*}{ Macela } & S. cholera- & Deco. $5 \%$ com reposição & 50 & $\leq 5.10^{4}$ & 24 & 5 & 3,33 & (1) \\
\hline & & suis $^{1}$ & Hidro. $10 \%$ com reposição & 50 & $\leq 5.10^{4}$ & 24 & 3,33 & 1,33 & \\
\hline & & S. enteritidis ${ }^{2}$ & Deco. 5\% sem reposição & 50 & $\leq 10^{7}$ & $24-144$ & 0 & 0 & (2) \\
\hline & & & Deco. $5 \%$ concentrado & 50 & $\leq 10^{7}$ & $24-144$ & 0 & 0 & \\
\hline & & & Hidro. $10 \%$ com reposição & 50 & $\leq 10^{7}$ & $24-144$ & 8,0 & 8,0 & \\
\hline $\begin{array}{l}\text { Allium porrum } \mathrm{L} \text {. } \\
\text { LILIACEAE }\end{array}$ & Alho-porró & S. enteritidis ${ }^{2}$ & Alco. $40 \%$ com reposição & 50 & $\leq 5.10^{4}$ & 72 & 8,0 & 8,0 & (3) \\
\hline \multirow[t]{3}{*}{$\begin{array}{l}\text { Allium tuberosum } \mathrm{L} . \\
\text { LILIACEAE }\end{array}$} & $\begin{array}{l}\text { Alho-nirá } \\
\text { Cebolinha } \\
\text { japonesa ou } \\
\text { chinesa }\end{array}$ & S. enteritidis ${ }^{2}$ & Alco. $40 \%$ com reposição & 50 & $\leq 5.10^{4}$ & 72 & 8,0 & 8,0 & (4) \\
\hline & \multirow[t]{2}{*}{ Jiucai } & S. enteritidis ${ }^{2}$ & Alco. $40 \%$ com reposição & 50 & $\leq 10^{5}$ & 24 & 8,0 & 7,0 & (5) \\
\hline & & & Deco. $100 \%$ & 50 & $\leq 10^{7}$ & $48-144$ & 8,0 & 8,0 & \\
\hline \multirow{4}{*}{$\begin{array}{l}\text { Aloysia gratissima } \\
\text { (Gill e Hook) Tronc. } \\
\text { VERBENACEAE }\end{array}$} & Garupá & S. enteritidis ${ }^{2}$ & Hidro. $10 \%$ com reposição & 50 & $\leq 5.10^{4}$ & $\begin{array}{c}24-144 \\
72\end{array}$ & $\overline{4}, 6$ & $\begin{array}{l}6,0 \\
1,3\end{array}$ & $(6)$ \\
\hline & Erva-de-N.-Sra. & & Alco. $40 \%$ com reposição & 50 & $\leq 5.10^{4}$ & 72 & 7,6 & 6,6 & (1) \\
\hline & Erva-santa & & Alco. c/ mat. org. $20 \%$ & 50 & $\leq 5.10^{7}$ & 01 & - & 4,0 & \\
\hline & Erva-da-pontada & & Deco. $10 \%$ com reposição & 50 & $\leq 5.10^{4}$ & 72 & 1,6 & 0 & \\
\hline $\begin{array}{l}\text { Arctium minus Hill } \\
\text { (Bernh.) }\end{array}$ & Bardana & S. enteritidis ${ }^{2}$ & Alco. $40 \%$ com reposição & 50 & $\leq 5.10^{4}$ & $24-120$ & 8,0 & - & (7) \\
\hline $\begin{array}{l}\text { ASTERACEAE } \\
\text { Artemisia } \\
\text { dracunculus L. var. } \\
\text { Inodora } \\
\text { ASTERACEAE }\end{array}$ & Estragão & S. enteritidis ${ }^{2}$ & Alco. $40 \%$ com reposição & 50 & $\leq 5.10^{4}$ & 72 & 8,0 & 0 & (3) \\
\hline Baccharis trimera & \multirow[t]{6}{*}{ Carqueja } & S. gallinarum & Deco. $1,5 \%$ sem reposição & 100 & $\leq 5.10^{4}$ & 24 & 8,0 & - & (8) \\
\hline (Less.) & & & & 100 & $\leq 5.10^{3}$ & 144 & 8,0 & - & \\
\hline \multirow{4}{*}{ COMPOSITAE } & & & & 100 & $\leq 0,5$ & 24 & 8,0 & - & \\
\hline & & S. cholera- & Deco. $5 \%$ com reposição & $30-50$ & $\leq 0,05$ & 24 & 8,0 & - & (1) \\
\hline & & suis $^{I}$ & Hidro. $10 \%$ com reposição & 50 & $\leq 5.10^{4}$ & 24 & 3,33 & 2,33 & \\
\hline & & & & 50 & $\leq 5.10^{4}$ & 24 & 4,0 & 2,0 & \\
\hline \multirow{2}{*}{$\begin{array}{l}\text { Bidens pilosa }(\mathrm{L} .) \\
\text { COMPOSITAE }\end{array}$} & \multirow[t]{2}{*}{ Picão-preto } & S. cholera- & Deco. $5 \%$ com reposição & 50 & $\leq 5.10^{4}$ & 24 & 0 & 0 & (1) \\
\hline & & suis $^{l}$ & Hidro. $10 \%$ com reposição & 50 & $\leq 5.10^{4}$ & 24 & 6,66 & 0 & \\
\hline \multirow{2}{*}{$\begin{array}{l}\text { Bryophyllum } \\
\text { pinnatum Kurz } \\
\text { CRASSULACEAE } \\
\text { Capsicum annuum }\end{array}$} & $\begin{array}{l}\text { Folha-da- } \\
\text { fortuna }\end{array}$ & S. enteritidis ${ }^{2}$ & Alco. $40 \%$ com reposição & 50 & $\leq 5.10^{4}$ & $24-120$ & 8,0 & - & (7) \\
\hline & $\begin{array}{l}\text { Pimenta de } \\
\text { jardim }\end{array}$ & S. enteritidis ${ }^{2}$ & Alco. $40 \%$ com reposição & 50 & $\leq 5.10^{4}$ & 72 & 5,0 & 3,0 & $\begin{array}{l}\text { (3) } \\
\text { (4) }\end{array}$ \\
\hline $\begin{array}{l}\text { Capsicum baccatum } \\
\text { L. SOLANACEAE }\end{array}$ & $\begin{array}{l}\text { Pimenta dedo } \\
\text { de moca }\end{array}$ & S. enteritidis ${ }^{2}$ & Alco. $40 \%$ com reposição & 50 & $\leq 5.10^{4}$ & 72 & 8,0 & 6,0 & $\begin{array}{l}\text { (3) } \\
\text { (4) }\end{array}$ \\
\hline $\begin{array}{l}\text { Capsicum frutescens } \\
\text { L. SOLANACEAE }\end{array}$ & $\begin{array}{l}\text { Pimenta } \\
\text { malagueta }\end{array}$ & S. enteritidis ${ }^{2}$ & Alco. $40 \%$ com reposição & 50 & $\leq 5.10^{4}$ & 72 & 8,0 & 8,0 & $\begin{array}{l}\text { (3) } \\
\text { (4) }\end{array}$ \\
\hline $\begin{array}{l}\text { Capsicum } s p . \\
\text { SOLANACEAE. }\end{array}$ & $\begin{array}{l}\text { Pimenta } \\
\text { calabresa (pool } \\
\text { de capsicum) }\end{array}$ & S. enteritidis ${ }^{2}$ & Alco. $40 \%$ com reposição & 50 & $\leq 5.10^{4}$ & 72 & 8,0 & 0 & (3) \\
\hline Casearia sylvestris & Chá-de-bugre & S. enteritidis ${ }^{2}$ & Deco. $5 \%$ sem reposição & $\geq 50$ & $\leq 40$ & 48 & 8,0 & - & (9) \\
\hline $\begin{array}{l}\text { Swartz- } \\
\text { FLACOURTIACEAE }\end{array}$ & Guaçatonga & & & & & & & & \\
\hline Chaptalia mutans & Arnica-do-mato & S. cholera- & Deco. $5 \%$ com reposição & 50 & $\leq 5.10^{4}$ & 24 & 0 & 0 & (1) \\
\hline $\begin{array}{l}\text { (L.) Polak. } \\
\text { ASTERACEAE }\end{array}$ & & suis $^{1}$ & Hidro. $10 \%$ com reposição & 50 & $\leq 5.10^{4}$ & 24 & 1,0 & 0 & \\
\hline Chenopodium album & Erva-do- & S. enteritidis ${ }^{2}$ & Alco. $40 \%$ com reposicão & 50 & $\leq 5.10^{4}$ & $24-72$ & 7,0 & - & (7) \\
\hline L. CHENOPODIACEAE & formigueiro & & & 50 & $\leq 5.10^{4}$ & $96-120$ & 6,0 & & \\
\hline $\begin{array}{l}\text { Commelina erecta } \\
\text { L. COMMELINACEAE }\end{array}$ & $\begin{array}{l}\text { Erva-de-santa- } \\
\text { Luzia }\end{array}$ & $\begin{array}{l}\text { S. cholera- } \\
\text { suis }^{1}\end{array}$ & Deco. $5 \%$ com reposição & 50 & $\leq 5.10^{4}$ & 24 & 0 & 0 & (1) \\
\hline & Trapoeraba & & Hidro. $10 \%$ com reposicão & 50 & $\leq 5.10^{4}$ & 24 & 3,33 & 0 & \\
\hline $\begin{array}{l}\text { Conyza bonairensis } \\
\text { (L.) Cronquist. }\end{array}$ & $\begin{array}{l}\text { Buva } \\
\text { voadeira }\end{array}$ & $\begin{array}{l}\text { S. cholera- } \\
\text { suis }^{1}\end{array}$ & Deco. $5 \%$ com reposição & 50 & $\leq 5.10^{4}$ & 24 & 0 & 0 & (1) \\
\hline COMPOSITAE & Erva-lanceta & & Hidro. $10 \%$ com reposição & 50 & $\leq 5.10^{4}$ & 24 & 5,0 & 1,66 & \\
\hline & Erva-carniceira & S. enteritidis ${ }^{2}$ & Alco. $40 \%$ com reposição & 50 & $\leq 5.10^{4}$ & $24-120$ & 0 & 0 & (7) \\
\hline Cordia curassavica & Erva-baleeira & S. cholera- & Deco. $5 \%$ com reposição & 50 & $\leq 5.10^{4}$ & 24 & 0 & 0 & (1) \\
\hline $\begin{array}{l}\text { (Jacq) Roem. \& Schult } \\
\text { ANGIOSPERMAE }\end{array}$ & & suis $^{1}$ & Hidro. $10 \%$ com reposição & 50 & $\leq 5.10^{4}$ & 24 & 1,66 & 0 & \\
\hline $\begin{array}{l}\text { Cuphea } \\
\text { carthagenensis (Jacq) }\end{array}$ & Sete-sangrias & S. enteritidis ${ }^{2}$ & Alco. $40 \%$ com reposição & 50 & $\leq 5.10^{4}$ & $24-120$ & 8,0 & - & (7) \\
\hline $\begin{array}{l}\text { Macbrd.ANGIOSPERMAE } \\
\text { Eichhornia } \\
\text { crassipes (Mart.) Solms } \\
\text { ANGIOSPERMAE }\end{array}$ & Aguapé & S. enteritidis ${ }^{2}$ & Alco. $40 \%$ com reposição & $\begin{array}{l}50 \\
50\end{array}$ & $\begin{array}{l}\leq 5.10^{4} \\
\leq 5.10^{4}\end{array}$ & $\begin{array}{l}24-48 \\
72-120\end{array}$ & $\begin{array}{l}1,0 \\
3,0\end{array}$ & - & (7) \\
\hline
\end{tabular}


...Continuação

Tabela 1. Plantas com indicativo etnográfico medicinal ou condimentar acessadas na região metropolitana de Porto Alegre, RS, que apresentaram alguma inibição ou inativação frente a Salmonella sp., segundo extração, dose-desafio e tempo de exposição

\begin{tabular}{|c|c|c|c|c|c|c|c|c|c|}
\hline Denom & Iação & & & & & & Res & ado & \\
\hline : & 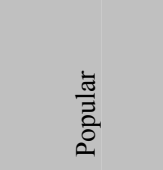 & 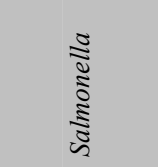 & 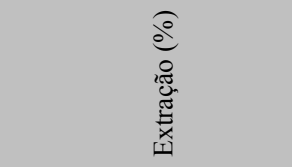 & 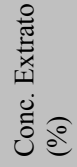 & 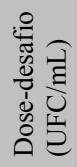 & 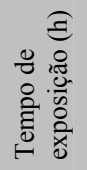 & 岂 & 离 & 苛 \\
\hline $\begin{array}{l}\text { Hypericum } \\
\text { caprifoliatum } \text { Cham. \& } \\
\text { Schult HYPERICACEAE/ } \\
\text { GUTTIFERAE }\end{array}$ & $\begin{array}{l}\text { Escadinha } \\
\text { Sinapismo }\end{array}$ & $\begin{array}{l}\text { S. cholera- } \\
\text { suis }^{1}\end{array}$ & $\begin{array}{l}\text { Deco. } 5 \% \text { com reposição } \\
\text { Hidro. } 10 \% \text { com reposição }\end{array}$ & $\begin{array}{l}50 \\
50\end{array}$ & $\begin{array}{l}\leq 5.10^{4} \\
\leq 5.10^{4}\end{array}$ & $\begin{array}{l}24 \\
24\end{array}$ & $\begin{array}{c}0 \\
3,33\end{array}$ & $\begin{array}{l}0 \\
0\end{array}$ & (1) \\
\hline $\begin{array}{l}\text { Ilex paraguariensis } \\
\text { A. St. Hill. } \\
\text { AQUIFOLIACEAE }\end{array}$ & Erva-mate & S. enteritidis ${ }^{2}$ & $\begin{array}{l}\text { Hidro.cambitos } 10 \% \text { c/reposição } \\
\text { Alco. de folhas } 40 \% \text { c/reposição } \\
\text { Deco. cambitos } 10 \% \text { c/reposição } \\
\text { Deco. de folhas } 10 \% \text { c/reposição } \\
\text { Deco. de cambitos c/mat. org. } \\
20 \% \text { c/reposição }\end{array}$ & $\begin{array}{l}50 \\
50 \\
50 \\
50 \\
50\end{array}$ & $\begin{array}{l}\leq 5.10^{5} \\
\leq 5.10^{5} \\
\leq 5.10^{5} \\
\leq 10^{7} \\
\leq 10^{7}\end{array}$ & $\begin{array}{l}72 \\
72 \\
72 \\
72 \\
01\end{array}$ & $\begin{array}{l}8,0 \\
8,0 \\
1,0 \\
1,0 \\
2,0\end{array}$ & $\begin{array}{c}6,67 \\
8,0 \\
0 \\
0 \\
3,0\end{array}$ & (10) \\
\hline $\begin{array}{l}\text { Ipomoea batatas L. } \\
\text { CONVOLVULACEAE }\end{array}$ & $\begin{array}{l}\text { Rama de batata } \\
\text { doce }\end{array}$ & S. enteritidis ${ }^{2}$ & Alco. $40 \%$ com reposição & 50 & $\leq 5.10^{4}$ & $24-120$ & 8,0 & - & (7) \\
\hline $\begin{array}{l}\text { Jacaranda micrantha } \\
\text { Cham. } \\
\text { BIGNONIACEAE }\end{array}$ & Caroba & $\begin{array}{l}\text { S. cholera- } \\
\text { suis }^{1}\end{array}$ & $\begin{array}{l}\text { Deco. } 5 \% \text { com reposição } \\
\text { Hidro. } 10 \% \text { com reposição }\end{array}$ & $\begin{array}{l}50 \\
50\end{array}$ & $\begin{array}{l}\leq 5.10^{4} \\
\leq 5.10^{4}\end{array}$ & $\begin{array}{l}24 \\
24\end{array}$ & $\begin{array}{c}5,66 \\
8,0\end{array}$ & $\begin{array}{c}3,66 \\
7,0\end{array}$ & (1) \\
\hline $\begin{array}{l}\text { Leandra australis } \\
\text { Cogn. } \\
\text { MELASTOMATACEAE }\end{array}$ & Pixirica & $\begin{array}{l}\text { S. cholera- } \\
\text { suis }^{1}\end{array}$ & $\begin{array}{l}\text { Deco. } 5 \% \text { com reposição } \\
\text { Hidro. } 10 \% \text { com reposição }\end{array}$ & $\begin{array}{l}50 \\
50\end{array}$ & $\begin{array}{l}\leq 5.10^{4} \\
\leq 5.10^{4}\end{array}$ & $\begin{array}{l}24 \\
24\end{array}$ & $\begin{array}{c}0 \\
2,0\end{array}$ & $\begin{array}{c}0 \\
2,0\end{array}$ & (1) \\
\hline $\begin{array}{l}\text { Luehea divaricata } \\
\text { Mart. TILIACEAE }\end{array}$ & Açoita-cavalo & $\begin{array}{l}\text { S. cholera- } \\
\text { suis }^{1}\end{array}$ & $\begin{array}{l}\text { Deco. } 5 \% \text { com reposição } \\
\text { Hidro. } 10 \% \text { com reposição }\end{array}$ & $\begin{array}{l}50 \\
50\end{array}$ & $\begin{array}{l}\leq 5.10^{4} \\
\leq 5.10^{4}\end{array}$ & $\begin{array}{l}24 \\
24\end{array}$ & $\begin{array}{c}0 \\
2,0\end{array}$ & $\begin{array}{c}0 \\
2,0\end{array}$ & (1) \\
\hline $\begin{array}{l}\text { Maytenus ilicifolia } \\
\text { Mat. ex Reiss. } \\
\text { CELASTRACEAE }\end{array}$ & $\begin{array}{l}\text { Espinheira-santa } \\
\text { Cancorosa }\end{array}$ & $\begin{array}{l}\text { S. cholera- } \\
\text { suis }^{1} \\
\text { S. enteritidis }{ }^{2}\end{array}$ & $\begin{array}{l}\text { Deco. } 5 \% \text { com reposição } \\
\text { Hidro. } 10 \% \text { com reposição } \\
\text { Alco. } 40 \% \text { com reposição }\end{array}$ & $\begin{array}{l}50 \\
50 \\
50 \\
50\end{array}$ & $\begin{array}{l}\leq 5.10^{4} \\
\leq 5.10^{4} \\
\leq 5.10^{4} \\
\leq 5.10^{4}\end{array}$ & $\begin{array}{c}24 \\
24 \\
24 \\
48-120\end{array}$ & $\begin{array}{c}0 \\
1,0 \\
4,0 \\
5,0\end{array}$ & $\begin{array}{l}0 \\
0 \\
- \\
-\end{array}$ & (7) \\
\hline $\begin{array}{l}\text { Myrciaria cuspidata } \\
\text { Berg. MYRTACEAE }\end{array}$ & Camboim & $\begin{array}{l}\text { S. cholera- } \\
\text { suis }^{1}\end{array}$ & $\begin{array}{l}\text { Deco. } 5 \% \text { com reposição } \\
\text { Hidro. } 10 \% \text { com reposição }\end{array}$ & $\begin{array}{l}50 \\
50\end{array}$ & $\begin{array}{l}\leq 5.10^{4} \\
\leq 5.10^{4}\end{array}$ & $\begin{array}{l}24 \\
24\end{array}$ & $\begin{array}{c}0 \\
5,33\end{array}$ & $\begin{array}{c}0 \\
4,0\end{array}$ & (1) \\
\hline $\begin{array}{l}\text { Ocimum basilicum } \mathrm{L} \text {. } \\
\text { LABIATAE }\end{array}$ & Manjericão & S. enteritidis ${ }^{2}$ & Alco. $40 \%$ com reposição & 50 & $\leq 10^{7}$ & $24 a 72$ & 8,0 & 7,0 & (10) \\
\hline $\begin{array}{l}\text { Ocimum gratissimum } \\
\text { L. LABIATAE }\end{array}$ & $\begin{array}{l}\text { Alfavaca } \\
\text { Erva-cravo }\end{array}$ & S. enteritidis ${ }^{2}$ & Alco. $40 \%$ com reposição & $\begin{array}{l}50 \\
50\end{array}$ & $\begin{array}{l}\leq 5.10^{4} \\
\leq 5.10^{4}\end{array}$ & $\begin{array}{c}24 \mathrm{a} 48 \\
72\end{array}$ & $\begin{array}{c}8,0 \\
8\end{array}$ & $\begin{array}{c}7,0 \\
8\end{array}$ & (10) \\
\hline $\begin{array}{l}\text { Ocimum selloi Benth. } \\
\text { LABIATAE }\end{array}$ & Anis verde & S. enteritidis ${ }^{2}$ & Alco. $40 \%$ com reposição & $\begin{array}{l}50 \\
50\end{array}$ & $\begin{array}{l}\leq 5.10^{4} \\
\leq 5.10^{4}\end{array}$ & $\begin{array}{c}24 \\
48-72\end{array}$ & $\begin{array}{l}8,0 \\
8,0\end{array}$ & $\begin{array}{l}6,0 \\
7,0\end{array}$ & (10) \\
\hline $\begin{array}{l}\text { Origanum applii } \\
\text { (Domin.) } \\
\text { Boros LABIATAE }\end{array}$ & $\begin{array}{l}\text { Manjerona } \\
\text { branca } \\
\text { Orégano }\end{array}$ & S. enteritidis ${ }^{2}$ & Deco. $5 \%$ sem reposição & $\begin{array}{l}\geq 15 \\
\geq 25 \\
50\end{array}$ & $\begin{aligned} & \leq 40 \\
& \leq 4.10^{2} \\
&<5.10^{4}\end{aligned}$ & $\begin{array}{l}48 \\
48 \\
72\end{array}$ & $\begin{array}{l}8,0 \\
8,0 \\
8,0\end{array}$ & $\begin{array}{c}- \\
- \\
8,0\end{array}$ & (12) \\
\hline $\begin{array}{l}\text { Origanum majorana } \\
\text { L. LABIATAE }\end{array}$ & $\begin{array}{l}\text { Manjerona } \\
\text { preta }\end{array}$ & S. enteritidis ${ }^{2}$ & Alco. $40 \%$ com reposição & 50 & $\leq 5.10^{4}$ & 72 & 2,0 & 0 & $\begin{array}{l}(4) \\
\text { (3) } \\
\text { (4) }\end{array}$ \\
\hline $\begin{array}{l}\text { Polygonum puctata } \\
\text { Ell. POLYGONACEAE }\end{array}$ & Erva-de-bicho & S. enteritidis ${ }^{2}$ & Alco. $40 \%$ com reposição & $\begin{array}{l}50 \\
50\end{array}$ & $\begin{array}{l}\leq 5.10^{4} \\
\leq 5.10^{4}\end{array}$ & $\begin{array}{c}24 \\
48-120\end{array}$ & $\begin{array}{l}5,0 \\
8,0\end{array}$ & - & (7) \\
\hline $\begin{array}{l}\text { Petroselinum sativum } \\
\text { H. UMBELIFERAE }\end{array}$ & Salsa verde & S. enteritidis ${ }^{2}$ & Alco. $40 \%$ com reposição & 50 & $\leq 5.10^{4}$ & 72 & 3,0 & 0 & $\begin{array}{l}(3) \\
\text { (4) }\end{array}$ \\
\hline $\begin{array}{l}\text { Rumex obtusifolius } \mathrm{L} . \\
\text { POLYGONACEAE }\end{array}$ & Língua-de-vaca & $\begin{array}{l}\text { S. cholera- } \\
\text { suis }^{1}\end{array}$ & $\begin{array}{l}\text { Deco. } 5 \% \text { com reposição } \\
\text { Hidro. } 10 \% \text { com reposição }\end{array}$ & $\begin{array}{l}50 \\
50\end{array}$ & $\begin{array}{l}\leq 5.10^{4} \\
\leq 5.10^{4}\end{array}$ & $\begin{array}{l}24 \\
24\end{array}$ & $\begin{array}{c}0 \\
2,0\end{array}$ & $\begin{array}{l}0 \\
0\end{array}$ & (1) \\
\hline $\begin{array}{l}\text { Sagittaria } \\
\text { montevidensis Cham. } \\
\text { \& Schltdl. } \\
\text { ANGIOSPERMAE }\end{array}$ & $\begin{array}{l}\text { Flecha, } \\
\text { Sagitária, } \\
\text { Aguapé-de-flecha }\end{array}$ & S. enteritidis ${ }^{2}$ & Hidro. $10 \%$ com reposição & 50 & $\leq 5.10^{4}$ & $24-120$ & 8,0 & - & (7) \\
\hline $\begin{array}{l}\text { Salvia officinalis } \mathrm{L} \text {. } \\
\text { LABIATEAE }\end{array}$ & Sálvia & S. enteritidis ${ }^{2}$ & Alco. $40 \%$ com reposição & 50 & $\leq 5.10^{4}$ & 72 & 8,0 & 8,0 & $\begin{array}{l}\text { (3) } \\
\text { (4) }\end{array}$ \\
\hline $\begin{array}{l}\text { Sedum dendroideum } \\
\text { Moc \& Sessé } \\
\text { CRASSULACEAE }\end{array}$ & Bálsamo & S. enteritidis ${ }^{2}$ & Alco. $40 \%$ com reposição & 50 & $\leq 5.10^{4}$ & $24-120$ & 8,0 & - & (7) \\
\hline $\begin{array}{l}\text { Similax brasiliensis } \\
\text { Spreng. LILIACEAE }\end{array}$ & Japecanga & $\begin{array}{l}\text { S. cholera- } \\
\text { suis }^{1} \\
\text { S. enteritidis }\end{array}$ & $\begin{array}{l}\text { Deco. } 5 \% \text { com reposição } \\
\text { Hidro. } 10 \% \text { com reposição } \\
\text { Alco. } 40 \% \text { com reposição }\end{array}$ & $\begin{array}{l}50 \\
50 \\
50 \\
50\end{array}$ & $\begin{array}{l}\leq 5.10^{4} \\
\leq 5.10^{4} \\
\leq 5.10^{4} \\
\leq 5.10^{4}\end{array}$ & $\begin{array}{c}24 \\
24 \\
24-48 \\
72-120\end{array}$ & $\begin{array}{c}0 \\
5,33 \\
6,0 \\
7,0\end{array}$ & $\begin{array}{l}0 \\
0 \\
- \\
-\end{array}$ & (1) \\
\hline $\begin{array}{l}\text { Solidago chilensis } \\
\text { Meyen COMPOSITAE }\end{array}$ & $\begin{array}{l}\text { Lanceta, } \\
\text { Federal, } \\
\text { Espiga-de-ouro }\end{array}$ & $\begin{array}{l}\text { S. cholera- } \\
\text { suis }^{1} \\
\text { S. enteritidis }\end{array}$ & $\begin{array}{l}\text { Deco. } 5 \% \text { com reposição } \\
\text { Hidro. } 10 \% \text { com reposição } \\
\text { Alco. } 40 \% \text { com reposição }\end{array}$ & $\begin{array}{l}50 \\
50 \\
50 \\
50\end{array}$ & $\begin{array}{l}\leq 5.10^{4} \\
\leq 5.10^{4} \\
\leq 5.10^{4} \\
\leq 5.10^{4}\end{array}$ & $\begin{array}{c}24 \\
24 \\
24 \\
48-120\end{array}$ & $\begin{array}{c}0 \\
0 \\
7,0 \\
8,0\end{array}$ & $\begin{array}{l}0 \\
0 \\
- \\
-\end{array}$ & (7) \\
\hline $\begin{array}{l}\text { Spirodela intermédia } \\
\text { W. Koch } \\
\text { ANGIOSPERMAE }\end{array}$ & Lentilha-d'água & S. enteritidis ${ }^{2}$ & Alco. $40 \%$ com reposição & 50 & $\leq 5.10^{4}$ & $24-120$ & 8,0 & - & (7) \\
\hline
\end{tabular}


...Continuação

Tabela 1. Plantas com indicativo etnográfico medicinal ou condimentar acessadas na região metropolitana de Porto Alegre, RS, que apresentaram alguma inibição ou inativação frente a Salmonella sp., segundo extração, dose-desafio e tempo de exposição

\begin{tabular}{|c|c|c|c|c|c|c|c|c|c|}
\hline Denom & lação & & & & & & Res & ido & \\
\hline : & 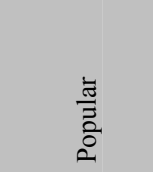 & 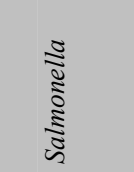 & 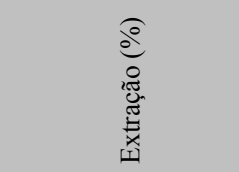 & 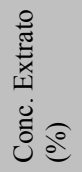 & 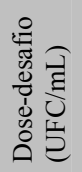 & 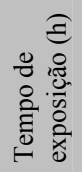 & 兰 & 离 & ֻัّ \\
\hline $\begin{array}{l}\text { Tabebuia } \\
\text { avellanedae Lor. ex } \\
\text { Griseb. } \\
\text { BIGNONIACEAE }\end{array}$ & $\begin{array}{l}\text { Ipê comum } \\
\text { Ipê rosa }\end{array}$ & $\begin{array}{l}\text { S.cholera- } \\
\text { suis }^{1}\end{array}$ & $\begin{array}{l}\text { Deco. } 5 \% \text { com reposição } \\
\text { Hidro. } 10 \% \text { com reposição }\end{array}$ & $\begin{array}{l}50 \\
50\end{array}$ & $\begin{array}{l}\leq 5.10^{4} \\
\leq 5.10^{4}\end{array}$ & $\begin{array}{l}24 \\
24\end{array}$ & $\begin{array}{c}0 \\
3,33\end{array}$ & $\begin{array}{l}0 \\
0\end{array}$ & (1) \\
\hline $\begin{array}{l}\text { Tagetes minuta } \mathrm{L} \text {. } \\
\text { COMPOSITAE }\end{array}$ & $\begin{array}{l}\text { Chinchilho } \\
\text { Picão-do-reino- } \\
\text { rojão }\end{array}$ & $\begin{array}{l}S . \\
\text { gallinarum }^{3}\end{array}$ & $\begin{array}{l}\text { Deco. } 10 \% \text { sem reposição } \\
\text { Deco. } 10 \% \text { com reposição }\end{array}$ & $\begin{array}{l}100 \\
50 \\
30\end{array}$ & $\begin{array}{l}\leq 5.10^{4} \\
\leq 0,5 \\
\leq 0,05\end{array}$ & $\begin{array}{l}24 \\
24 \\
24\end{array}$ & $\begin{array}{l}8,0 \\
8,0 \\
8,0\end{array}$ & $\begin{array}{l}- \\
-\end{array}$ & (13) \\
\hline $\begin{array}{l}\text { Thymus citriodorus } \\
\text { L. LABIATAE }\end{array}$ & $\begin{array}{l}\text { Tomilho } \\
\text { citronela }\end{array}$ & S. enteritidis ${ }^{2}$ & Alco. $40 \%$ com reposição & 50 & $\leq 5.10^{4}$ & 72 & 4,0 & 0 & $\begin{array}{l}\text { (3) } \\
\text { (4) }\end{array}$ \\
\hline $\begin{array}{l}\text { Tibouchina } \\
\text { longipilosa Cong. } \\
\text { Berg. } \\
\text { MELASTOMATACEAE }\end{array}$ & $\begin{array}{l}\text { Pixirica do } \\
\text { campo }\end{array}$ & $\begin{array}{l}\text { S. cholera- } \\
\text { suis }^{1}\end{array}$ & $\begin{array}{l}\text { Deco. } 5 \% \text { com reposição } \\
\text { Hidro. } 10 \% \text { com reposição }\end{array}$ & $\begin{array}{l}50 \\
50\end{array}$ & $\begin{array}{l}\leq 5.10^{4} \\
\leq 5.10^{4}\end{array}$ & $\begin{array}{l}24 \\
24\end{array}$ & $\begin{array}{c}0 \\
3,0\end{array}$ & $\begin{array}{c}0 \\
3,0\end{array}$ & (1) \\
\hline $\begin{array}{l}\text { Tillandsia usneoides } \\
\text { L. BROMELIACEAE }\end{array}$ & Barba-de-pau & $\begin{array}{l}\text { S. cholera- } \\
\text { suis }^{1}\end{array}$ & $\begin{array}{l}\text { Deco. } 5 \% \text { com reposição } \\
\text { Hidro. } 10 \% \text { com reposição }\end{array}$ & $\begin{array}{l}50 \\
50\end{array}$ & $\begin{array}{l}\leq 5.10^{4} \\
\leq 5.10^{4}\end{array}$ & $\begin{array}{l}24 \\
24\end{array}$ & $\begin{array}{c}0 \\
2,66\end{array}$ & $\begin{array}{l}0 \\
0\end{array}$ & (1) \\
\hline $\begin{array}{l}\text { Vernonia condensata } \\
\text { Baker ASTERACEAE }\end{array}$ & $\begin{array}{l}\text { Orô } \\
\text { Alumã }\end{array}$ & S. enteritidis ${ }^{2}$ & Alco. $40 \%$ com reposição & 50 & $\leq 5.10^{4}$ & $24-120$ & 1,0 & - & (7) \\
\hline $\begin{array}{l}\text { Vernonia scorpioides } \\
\text { Lam. ASTERACEAE }\end{array}$ & $\begin{array}{l}\text { Erva-de- São- } \\
\text { Simão } \\
\text { Erva-de-preta- } \\
\text { velha }\end{array}$ & S. enteritidis ${ }^{2}$ & $\begin{array}{l}\text { Deco. } 5 \% \text { com reposição } \\
\text { Hidro. } 10 \% \text { com reposição }\end{array}$ & $\begin{array}{l}50 \\
50\end{array}$ & $\begin{array}{l}\leq 5.10^{4} \\
\leq 5.10^{4} \\
\leq 5.10^{4}\end{array}$ & $\begin{array}{c}24-120 \\
24 \\
24\end{array}$ & $\begin{array}{c}8,0 \\
0 \\
0\end{array}$ & $\begin{array}{l}- \\
0 \\
0\end{array}$ & (7) \\
\hline
\end{tabular}

Especificamente dentre as plantas com indicativo condimentar destacam-se estragão (Artemísia dracunculus $L$. var. inodora) e pimenta calabresa (pool de Capsicum sp.) por apresentarem inibição (bacteriostasia) grau máximo oito, porém inativação (bactericidia) grau mínimo zero. À luz dessa constatação, Carvalho et al. (2006) demonstraram a baixa preditividade dos resultados negativos de pesquisa de salmonela em simulação alimentar condimentada com estragão, devendo tais resultados serem interpretados como falso-negativos, permitindo recomendar o acréscimo dos desinibidores bacterianos (Deutsche..., 1980, citado por Schliesser e Strauch, 1981 ) à técnica oficial de pesquisa de salmonela em alimentos em vigor no país, além da inclusão da busca de indicativos epidemiológicos descritivos sobre possíveis condimentações dos alimentos envolvidos nos surtos toxinfectivos sob investigação, fundamentando assim a preditividade dos possíveis resultados negativos por inibição provocada pelos diferentes condimentos vegetais.

As técnicas de diluição e de suspensão, por sua vez, por meio de sistema de tubos múltiplos, demonstraram acuidade ao se reproduzirem resultados semelhantes mesmo com diferentes acessos de planta, após três a seis anos de intervalo, no exemplo de alho-nirá ou jiucai (Allium tuberosum) e de macela (Achyrocline satureoides).

Por outro lado, analisando especificamente os resultados da baleeira (Cordia curassavica), há evidências de que o tipo de extração influencia a eficácia antibacteriana do extrato, pela possível perda de elementos bioativos na decocção e/ou na pré-secagem da planta antes da confecção de hidroalcoolatura, o que parece não ocorrer na técnica de extração por alcoolatura a partir de plantas verdes, recém-colhidas. 
Inibição e inativação...

Tabela 2. Plantas com indicativo etnográfico medicinal ou condimentar acessadas na região metropolitana de Porto Alegre, RS que apresentaram nenhuma inibição ou inativação frente a Salmonella sp., segundo a forma de extração

\begin{tabular}{|c|c|c|c|}
\hline \multicolumn{2}{|l|}{ Denominação } & \multirow{2}{*}{ Forma de extração } & \multirow{2}{*}{ Fonte } \\
\hline Científica & Popular & & \\
\hline Acanthospermum australe (Loefl.) Kuntze & Carrapicho rasteiro & Deco. $5 \%$ com reposição & Avancini (2002) \\
\hline ASTERACEAE & Mata-pasto & Hidro. $10 \%$ com reposição & \\
\hline Allium fistulosum L. LILIACEAE & Cebola-todo-ano & Alco. $40 \%$ com reposição & Carvalho (2004) \\
\hline Allium sativum L. LILIACEAE & Alho-macho & Hidro. $10 \%$ com reposição & Carvalho (2004) \\
\hline Allium schoenoprasum L. LILIACEAE & Cebolinha verde & Alco. $40 \%$ com reposição & Carvalho (2004) \\
\hline Alternanthera dentata (Moench.) Stuchl. & Penicilina & Deco. $5 \%$ com reposição & Avancini (2002) \\
\hline AMARANTHACEAE & & Hidro. $10 \%$ com reposição & \\
\hline Anethum graveoleus L. UMBELLIFERAE & Endro & Alco. $40 \%$ com reposição & Carvalho (2004) \\
\hline \multirow[t]{2}{*}{ Apium leptophyllum (Pers.) F. APIACEAE } & Aipinho & Deco. $5 \%$ com reposição & Avancini (2002) \\
\hline & Erva-do-teto & Hidro. $10 \%$ com reposição & \\
\hline Calea serrata Less. ASTERACEAE & Quebra-tudo & $\begin{array}{l}\text { Deco. } 5 \% \text { com reposição } \\
\text { Hidro. } 10 \% \text { com reposição }\end{array}$ & Avancini (2002) \\
\hline Capsicum anпuит L. SOLANACEAE & Pimentão amarelo & Alco. $40 \%$ com reposição & Carvalho (2004) \\
\hline Capsicum anпuит L. SOLANACEAE & Pimentão verde & Alco. $40 \%$ com reposição & Carvalho (2004) \\
\hline Capsicum annuиm L. SOLANACEAE & Pimentão vermelho & Alco. $40 \%$ com reposição & Carvalho (2004) \\
\hline Capsicum baccatum L. SOLANACEAE & Pimenta-cambuci & Alco. $40 \%$ com reposição & Carvalho (2004) \\
\hline Clystostoma callistegioides (Cham.) Bur. & Cipó-ouro & Deco. 5\% com reposição & Avancini (2002) \\
\hline BIGNONIACEAE & & Hidro. $10 \%$ com reposição & \\
\hline Coriandrum sativum L. UMBELLIFERAE & Coentro & Alco. $40 \%$ com reposição & Carvalho (2004) \\
\hline Croton gnaphalii Baill & Erva-da-graça & Deco. $5 \%$ com reposição & Avancini (2002) \\
\hline EUPHOR BIACEAE & & Hidro. $10 \%$ com reposição & \\
\hline Cyperus brevifolius (Rottb.) Hassk. & Junquinho & Deco. $5 \%$ com reposição & Avancini (2002) \\
\hline \multirow{3}{*}{ CYPERACEAE } & Chufa & Hidro. $10 \%$ com reposição & \\
\hline & Sulfa & & \\
\hline & Capim-limão & & \\
\hline \multirow[t]{3}{*}{ Cyperus ferax Rich. CYPERACEAE } & Junça & Deco. $5 \%$ com reposição & Avancini (2002) \\
\hline & Tiriricão & Hidro. $10 \%$ com reposição & \\
\hline & Junquinho & & \\
\hline Desmodium adscendens (Sw.) DL & Carrapicho-beiço-de-boi & Deco. 5\% com reposição & Avancini (2002) \\
\hline \multirow[t]{2}{*}{ ANGIOSPERMAE } & Pega-pega & Hidro. $10 \%$ com reposição & \\
\hline & Amor-de-mulher & & \\
\hline Eryngium horridum Malme & Caraguatá & Deco. 5\% com reposição & Avancini (2002) \\
\hline ANGIOSPERMAE & Gravatá & Hidro. $10 \%$ com reposição & \\
\hline Eupatorium laevigatum Lam. & Erva-formigueira & Deco. $5 \%$ com reposição & Avancini (2002) \\
\hline ASTERACEAE & Cambará falso & Hidro. $10 \%$ com reposição & \\
\hline Lycopersicon sp. L. SOLANACEAE & Tomate-silvestre & Alco. $40 \%$ com reposição & Carvalho (2004) \\
\hline Lycopersicon sp. L. SOLANACEAE & Tomate-cereja I (ovalado) & Alco. $40 \%$ com reposição & Carvalho (2004) \\
\hline Lycopersicon sp. L. SOLANACEAE & Tomate-cereja II (redondo) & Alco. $40 \%$ com reposição & Carvalho (2004) \\
\hline Lycopersicon sp. L. SOLANACEAE & $\begin{array}{l}\text { Tomate-cereja III } \\
\text { (redondo) }\end{array}$ & Alco. $40 \%$ com reposição & Carvalho (2004) \\
\hline Melissa officinalis L. LABIATAE & Melissa & Alco. $40 \%$ com reposição & Carvalho (2004) \\
\hline Petroselinum crispum $H$. LABIATAE & Salsa crespa (raiz) & Alco. $40 \%$ com reposição & Carvalho (2004) \\
\hline Piper nigrum L. PIPERACEAE & Pimenta-preta & Alco. $40 \%$ com reposição & Carvalho (2004) \\
\hline Piper sp. L. PIPERACEAE & Pimenta-branca & Alco. $40 \%$ com reposição & Carvalho (2004) \\
\hline Pistia stratioides L. ANGIOSPERMAE & Alface-de-água & Alco. $40 \%$ com reposição & Gonçalves (2005) \\
\hline Pterocaulum cordobense O. Ktze. & Calção-de-velho & Deco. 5\% com reposição & Avancini (2002) \\
\hline ASTERACEAE & Verbasco & Hidro. $10 \%$ com reposição & \\
\hline Rosmarinus officinalis L. LABIATAE & Alecrim & Alco. $40 \%$ com reposição & Carvalho (2004) \\
\hline Sambucus australis Cham. \& Schlecht & Sabugueiro & Deco. $5 \%$ com reposição & Avancini (2002) \\
\hline CAPRIFOLIACEAE & & Hidro. $10 \%$ com reposição & \\
\hline Solanum sisymbriifolium Lam. & Joá & Deco. $5 \%$ com reposição & Avancini (2002) \\
\hline SOLANACEAE & Mata-cavalo & Hidro. $10 \%$ com reposição & \\
\hline Solanum mauritianum Seop. & Fumo-brabo & Deco. $5 \%$ com reposição & Avancini (2002) \\
\hline SOLANACEAE & & Hidro. $10 \%$ com reposição & \\
\hline Thymus vulgaris L. LAMIACEAE & Tomilho & Alco. $40 \%$ com reposição & Carvalho (2004) \\
\hline Zinziber officinale L. ZINZIBERACEAE & Gengibre & Alco. $40 \%$ com reposição & Carvalho (2004) \\
\hline
\end{tabular}

Alco. $=$ alcoolatura; Deco. $=$ decocto; Hidro. $=$ hidroalcoolatura. 
A triagem de agentes medicinais ativos em plantas, não obrigatoriamente antimicrobianos, segundo Malone (1983), permite atingir escores de 1:10, ou seja, $10 \%$ de plantas com alguma atividade evidenciada, dentre o total de plantas pesquisadas com indicativo etnográfico de uso medicinal tradicional. Nesse sentido, como participantes deste Grupo de Pesquisa, Avancini (2002) alcançou percentual de acertos de 51,4\%, Carvalho (2004) atingiu 37,5\%, e Gonçalves (2005), 88,8\% de acertos. No presente estudo, dentre as 86 plantas testadas no período (1995-2008), atingiu-se escore de $58,1 \%$ de acertos específicos em relação à salmonela, sinalizando a validação do resgate etnográfico como ferramenta na prospecção de plantas medicinais como fatores de proteção antibacteriana, com base em de saberes tradicionais compartilhados.

Considerando que a seleção dessas plantas fundamentou-se no resgate e na valoração de seus indicativos etnográficos de uso medicinal, condimentar ou aromático junto a diferentes parceiros-informantes tradicionais, considerando, outrossim, a confirmação dessas indicações em $58,1 \%$ das plantas por meio dos resultados da triagem apresentados, este trabalho pretende situarse na interface entre diferentes saberes, vinculando o senso comum e o senso científico relativo às plantas medicinais condimentares e aromáticas como recursos antibacterianos naturais renováveis e, possíveis fatores de proteção cientificamente assegurados, socialmente aceitáveis e ecologicamente sustentáveis, nos princípios da atenção básica em saúde (Cultura..., 1984, 1985, 1990). Pretende-se, ainda, oferecer suporte a indagações a respeito dos princípios ativos intervenientes, da sensibilidade de outros microrganismos emergentes, ou mesmo da possibilidade de intervenção em situações-problema específicas na realidade concreta das diferentes cadeias produtivas.

\section{AGRADECIMENTO}

Aos informantes, pela partilha do conhecimento tradicional. Ao CNPq, pelo estímulo e financiamento contínuos. A FAPERGS, pelo financiamento ao projeto.

\section{REFERÊNCIAS BIBLIOGRÁFICAS}

ACHA, P.N.; SZYFRES, B. Zoonosis and communicable diseases common to men and animals: bacteriosis and mycosis. 3.ed. Washington: World Health Organization. $398 \mathrm{p}$.
AKERELE, O. Las plantas medicinales: un tesoro que no debemos desperdiciar. Foro Mund. Salud, v.14, p.390395,1993

AKERELE, O. Medicinal plants and primary health care: an agend for action. Fitoterapia, v.59, p.355-363, 1988

ALVARENGA, A.L.; SCHWAN, R.F.; DIAS, D.R. et al. Atividade antimicrobiana de extratos vegetais sobre bactérias patogênicas humanas. Rev. Bras. Plantas Med., v.9, p.86-91, 2007

ARAUJO, C.D. Atividade antibacteriana in vitro $e$ in sito de Allium tuberosum - Rottler ex Spengl (alho "nirá", alho "japonês", "jiucai", alho "chinês") - Liliaceae sobre agentes de toxinfecções alimentares. 2007. 85f. Dissertação (Mestrado) - Faculdade de Veterinária, Universidade Federal do Rio Grande do Sul, Porto Alegre.

AVANCINI, C.A.M. Desinfecção em saúde e produção animal: bacteriostasia e bactericidia de Baccharis trimera (Less.) D.C. - Compositae - ("carqueja") frente a microorganismos entéricos e cutâneos. 1995. 152f. Dissertação (Mestrado) - Faculdade de Veterinária, Universidade Federal do Rio Grande do Sul, Porto Alegre.

AVANCINI, C.A.M. Saneamento aplicado em saúde e produção animal: etnografia, triagem da atividade antibacteriana de plantas nativas no sul do Brasil e testes de avaliação do decocto de Hypericum caprifoliatum Cham. e Schlecht. - Hypericaceae (Guttiferae) ("escadinha", "sinapismo") para uso como desinfetante e antisséptico. 2002. 309f. Tese (Doutorado) - Faculdade de Veterinária, Universidade Federal do Rio Grande do Sul, Porto Alegre.

AVANCINI, C.A.M.; WIEST, J.M. Atividade desinfetante do decocto de Hypericum caprifoliatum Cham. e Shclecht. - Guttiferae ("escadinha/sinapismo"), frente a diferentes doses infectantes de Staphylococcus aureus (agente infeccioso de mastite bovina). Rev. Bras. Plantas Med., v.10, p.90-98, 2008a.

AVANCINI, C.A.M.; WIEST, J.M. Etnomedicina veterinária, etnonosotaxia e etnoterapêutica de doenças de pele como referência para seleção e avaliação preliminar da atividade antibacteriana de plantas nativas do Sul do Brasil. Rev. Bras. Plantas Med., v.10, p.70-78, 2008b.

AVANCINI,C.A.M.; WIEST, J.M.; MUNDSTOCK, E. Atividade bacteriostática e bactericida do decocto de Baccharis trimera (Less.) D.C., Compositae - carqueja como desinfetante ou antisséptico. Arq. Bras. Med. Vet. Zootec., v.52, p.230-234, 2000.

BEDIN, C. Atividade antibacteriana in vitro do decocto de Origanum applii (Domin.)Boros - Labiatae ("orégano", “manjerona”) sobre agentes de interesse em alimentos. 1998. 90 f. Dissertação (Mestrado) Faculdade de Veterinária, Universidade Federal do Rio Grande do Sul, Porto Alegre.

CARVALHO, H.H.C.; CRUZ, F.T.; WIEST, J.M. Atividade antibacteriana em plantas com indicativo 
etnográfico condimentar em Porto Alegre, RS/Brasil. Rev. Bras. Plantas Med., v.7, p.25-32, 2005.

CARVALHO, H.H.C.; WIEST, J.M.; GRECO, D.P. Atividade antibacteriana e a preditividade do condimento Artemisia dracunculus Linn. (Asteraceae), variedade inodora - estragão - frente a Salmonella sp. Cienc. Tecnol. Aliment., v.26, p.75-79, 2006.

CARVALHO, H.H.C. Avaliação da atividade antibacteriana de plantas com indicativo etnográfico condimentar. 2004. 200f. Tese (Doutorado) - Faculdade de Veterinária, Universidade Federal do Rio Grande do Sul, Porto Alegre.

CASTAGNA, S.M.F.; SCHWARZ, C.W.; CANAL, C.W. et al. Presença de Salmonella sp. no trato intestinal e em tonsilas/linfonodos submandibulares de suínos ao abate. Arq. Bras. Med. Vet. Zootec., v.56, p.300-306, 2004.

CLOTET, J.; GOLDIM, J.R.; FRANCISCONI, C.F. Consentimento informado. Porto Alegre: PUC-RS, 2000. $130 \mathrm{p}$.

CULTURA medica tradicional. Bol. Ofic. Sant. Panam., v.96, p.180-181, 1984.

CULTURA medica tradicional. Bol. Ofic. Sant. Panam., v.98, p.373-377, 1985.

CULTURA médica tradicional. Bol. Ofic. Sant. Panam., v. 108, p. $77-80,1990$

DEUTSCHE Veterinärmedizinische Gesellschaft. Richtlinien für die Prüfung chemischer Desinfektionsmittel der DVG. Giessen: Eigenverlag, 1980.

ETKIN, N.L. Anthropological methods in ethnopharmacology. J. Ethnopharmacol., v.38, p.93-104, 1993.

FARMACOPEIA dos Estados Unidos do Brasil. 2.ed. São Paulo: Siqueira, 1959. 532p.

GIROLOMETTO, G. Avaliação $d a$ atividade antibacteriana de extratos de Ilex paraguaiensis $A$. ST.Hill.- Aquifoliaceae - ("erva-mate") frente a bactérias zoonóticas em saúde e produção animal. 2005. 71f. Dissertação (Mestrado) - Faculdade de Veterinária, Universidade Federal do Rio Grande do Sul, Porto Alegre.

GONÇALVES, A.R. Fitodesinfecção aplicada à água na perspectiva da agricultura e da agroindústria familiar. 2005. 130f. Tese (Doutorado) - Faculdade de Veterinária, Universidade Federal do Rio Grande do Sul, Porto Alegre.

GUTKOSKI, S. Atividade antibacteriana in vitro do decocto de Casearia sylvestris , Swartz - Flacourtiaceae ("chá-de- bugre", "guaçatonga") sobre agentes de interesse em saúde animal e saúde coletiva. 1999. 84f. Dissertação (Mestrado) - Faculdade de Veterinária, Universidade Federal do Rio Grande do Sul, Porto Alegre.
LEMOS, G.C.S.; OLIVEIRA, L.O.; EBERLI, B.B. et al. Bacterial activity of macela (Achyrocline satureioides (Lam.) DC.) against strains of Staphylococcus aureus isolated from subclinical bovine mastitis. Rev. Bras. Plantas Med., v.3, p.67-72, 2000.

MALONE, M.H. The pharmacological evaluation of natural products: general and specific approaches to screening ethnopharmaceuticals. J. Ethnopharmacol., v.8, p.127-147, 1983.

MING, L.C. Coleta de plantas medicinais. In: DI STASI, L.C. Plantas medicinais arte e ciência: um guia de estudo interdisciplinar. São Paulo: UNESP, 1996. p.69-86.

MOTA, F.M. Atividade antibacteriana in vitro de inflorescências de Achyrocline satureoides (Lam.) DC. Asteraceae - ("macela", "marcela") como fator de proteção em zoonoses. 2008. 91f. Dissertação (Mestrado) - Faculdade de Veterinária, Universidade Federal do Rio Grande do Sul, Porto Alegre.

SCHLIESSER, Th.; STRAUCH, D. Desinfektion in Tierhaltung, Fleisch- und Milchwirtschaft. Stuttgart: Enke Verlag, 1981. 455p.

SILVA, L.E.; GOTARDI, C.P.; VIZZOTO, J.D. et al. Infecção por Salmonella enterica em suinos criados em um sistema integrado de produção do Sul do Brasil. Arq. Bras. Med. Vet. Zootec., v.58, p.455-461, 2006.

SOUTO, S.A.; SOBREIRO, A.A.; CARVALHO, H.H.C. et al. Atividade antibacteriana in vitro de plantas condimentares do gênero Ocimum - Labiatae (O.selloi Benth. - anis verde; $O$. basilicum L. - manjericão; $O$. gratissimum L. - erva-cravo, alfavaca), frente a zoonoses transmissíveis por alimentos. In: SALÃO DE INICIAÇÃO CIENTÍFICA DA UNIVERSIDADE FEDERAL DO RIO GRANDE DO SUL, 18., 2006, Porto Alegre. Anais... Porto Alegre: UFRGS, 2006.

SOUZA, A.A. Aspectos etnobiológicos e avaliação da atividade antibacteriana de Aloysia gratissima (Gill et Hook )Tronc. - Verbenaceae - ("garupá", "erva santa") sobre agentes de importância em saúde e produção animal. 2005. 87f. Dissertação (Mestrado) - Faculdade de Veterinária, Universidade Federal do Rio Grande do Sul, Porto Alegre.

SOUZA, C.A.S.; AVANCINI, C.A.M.; WIEST, J.M. Atividade antimicrobiana de Tagetes minuta L.Compositae - (chinchilho) frente a bactérias Grampositivas e Gram-negativas. Braz. J. Vet. Res. Anim. Sci., v.37, p.1-9, 2000.

SOUZA, A.A.; WIEST, J.M. Atividade antibacteriana de Aloysia gratissima (Gill et Hook) Tronc. (garupá, erva santa) usada na medicina tradicional no Rio Grande do Sul - Brasil. Rev. Bras. Plantas Med., v.9, p.23-29, 2007.

SOUZA, C.A.S. Aspectos etnobiológicos e atividade antibacteriana in vitro de Tagetes minuta L.- Compositae - chinchilho. 1998. 11f. Dissertação (Mestrado) Faculdade de Veterinária, Universidade Federal do Rio Grande do Sul, Porto Alegre. 